\title{
Range of ventricular dimensions and function by steady-state free precession cine cardiac magnetic resonance in patients late after the Fontan operation
}

\author{
Rahul H Rathod ${ }^{1 *}$, Yuli Y Kim², Ashwin Prakash', Ioannis Germanakis ${ }^{3}$, Andrew J Powell', Tal Geva ${ }^{1}$ \\ From 15th Annual SCMR Scientific Sessions \\ Orlando, FL, USA. 2-5 February 2012
}

\section{Summary}

To characterize the range of ventricular size and function evaluated by steady-state free precession (SSFP) cine cardiac magnetic resonance (CMR) in functional single ventricle (FSV) patients late after Fontan operation and to identify factors associated with FSV dysfunction.

\section{Background}

Ventricular size and function is important in patients with FSV after Fontan and adverse remodeling has been associated with poor clinical outcomes. Due to the limitations of echocardiography and other noninvasive techniques, CMR remains the gold standard for the assessment of ventricular size and function. However, the range and distribution of FSV size and function in this population has not been characterized in a large cohort across a broad range of ages using contemporary SSFP techniques.

\section{Methods}

All patients at our center following a Fontan operation who had a CMR study from $4 / 2002$ to $1 / 2011$ were retrospectively reviewed. In patients with multiple CMR studies, the most recent study was used for analysis. If 2 ventricles were present and connected to the systemic circulation, the end-diastolic (EDV) and end-systolic (ESV) volumes were summated to describe total effective volumetric and function data. Examinations were performed on a $1.5 \mathrm{~T}$ scanner using a standardized,

'Department of Cardiology, Children's Hospital Boston, Boston, MA, USA Full list of author information is available at the end of the article previously published imaging protocol. Combined $E D V_{i}$, $E S V_{i}$, and ventricular mass index (Mass ${ }_{i}$ ) were indexed to $\mathrm{BSA}^{1.3}$. Other clinically relevant data including demographic information, cardiac diagnoses, surgical history, and clinical symptoms and outcomes were recorded. Ventricular dysfunction was defined as ejection fraction $(\mathrm{EF}) \leq 45 \%$ and variables associated with FSV dysfunction were analyzed.

\section{Results}

Of the 261 patients who had a CMR study after the Fontan operation, 46 (18\%) had incomplete data due to metallic artifacts from coils and other devices. The median age at CMR of the remaining 215 patients was 18.3 years [13.6, 26.1], age at Fontan 3.6 years [2.3, 7.1], and the median time since Fontan was 14.6 years $[9.5,19.3]$. LV morphology was present in $45 \%$ of patients, RV morphology in $30 \%$, and biventricular in $25 \%$. The lateral tunnel Fontan operation was performed in $70 \%$ of patients, right atrium to pulmonary artery in $21 \%$, extracardiac in $5 \%$, and right atrium to right ventricle in $4 \%$. The medians, interquartile range (IQR), means, standard deviations (SD), and ranges of FSV size and function are summarized in Table 1. Compared with patients without FSV dysfunction $(n=174)$, those with dysfunction $(n=41)$ were older at the time of Fontan $(4.9$ v. 3.4 years, $p=0.026)$, older at time of CMR (22.3 v. 17.4 years, $p=0.02$ ), and had higher frequencies of $\geq$ moderate atrioventricular valve regurgitation $(27 \%$ v. $7.5 \%, p=0.001)$, non-sustained ventricular tachycardia $(27 \%$ v. $12 \%$, $p=0.023)$, and stroke (32\% v. $16 \%, p=0.025)$. 
Table 1 SSFP measurements of ventricular size and function in Fontan patients

\begin{tabular}{cccc}
\hline CMR Measurement & Median [IQR] & Mean \pm SD & Range \\
\hline $\mathrm{EDV}_{\mathrm{i}}\left(\mathrm{ml}^{\left.\mathrm{B} S \mathrm{BS}^{1.3}\right)}\right.$ & $94[76,116]$ & $94 \pm 44$ & $39-359$ \\
$\mathrm{ESV}_{\mathrm{i}}\left(\mathrm{ml}^{\mathrm{BSSA}}{ }^{1.3}\right)$ & $42[32,57]$ & $50 \pm 34$ & $11-277$ \\
$\mathrm{EF}(\%)$ & $55[47,61]$ & $54 \pm 10$ & $13-78$ \\
Mass $_{\mathrm{i}}\left(\mathrm{g} / \mathrm{BSA}^{1.3}\right)$ & $55[43,68]$ & $60 \pm 24$ & $17-181$ \\
Mass:Volume ratio & $0.57[0.48,0.69]$ & $0.63 \pm 0.26$ & $0.25-2.3$ \\
\hline
\end{tabular}

\section{Conclusions}

This study provides the range and distribution of ventricular size and function in a large cohort of patients late after the Fontan operation using contemporary CMR techniques and demonstrates important variations in those patients with significant systolic dysfunction.

\section{Funding}

None.

\section{Author details}

${ }^{1}$ Department of Cardiology, Children's Hospital Boston, Boston, MA, USA.

${ }^{2}$ Department of Cardiology, Hospital of the University of Pennsylvania and Children's Hospital of Philadelphia, Philadelphia, PA, USA. ${ }^{3}$ Department of

Pediatrics, University Hospital Heraklion, Heraklion, Greece.

Published: 1 February 2012

doi:10.1186/1532-429X-14-S1-P105

Cite this article as: Rathod et al:: Range of ventricular dimensions and

function by steady-state free precession cine cardiac magnetic

resonance in patients late after the Fontan operation. Journal of

Cardiovascular Magnetic Resonance 2012 14(Suppl 1):P105.

Submit your next manuscript to BioMed Central and take full advantage of:

- Convenient online submission

- Thorough peer review

- No space constraints or color figure charges

- Immediate publication on acceptance

- Inclusion in PubMed, CAS, Scopus and Google Scholar

- Research which is freely available for redistribution

Submit your manuscript at www.biomedcentral.com/submit 